\title{
Nanosheet architectonics: a hierarchically structured assembly for tailored fusion materials
}

\author{
Minoru Osada and Takayoshi Sasaki
}

Hierarchical self-assembly is a ubiquitous process in nature that underlies the formation of complex biological structures. In recent decades, scientists have aspired to exploit biomimetic approaches to create new artificial materials with hierarchical structures and tailored properties. However, de novo design of such hierarchically structured materials is still a major challenge. In this Focus Review, we provide an overview of new design principles for hierarchical nanoarchitectures using a layer-by-layer (LbL) assembly of two-dimensional (2D) oxide nanosheets. 2D oxide nanosheets have remarkable potential as building blocks for tailoring fusion materials combined with a range of foreign materials such as organic molecules, gels, polymers, and inorganic and metal nanoparticles. The ability to create functionalized, 2D hierarchical systems will lead to various applications in optoelectronics, spinelectronics, energy and environment technologies.

Polymer Journal (2015) 47, 89-98; doi:10.1038/pj.2014.111; published online 10 December 2014

\section{INTRODUCTION}

Hierarchical self-assembly of organic/inorganic layers is a hallmark of biological materials. ${ }^{1-3}$ Nacre, the inner iridescent layer of mollusc shells, has been heralded as a model system of such assembly, and it has been investigated for many decades owing to its exceptional mechanical properties stemming from its unique lamellar structures. ${ }^{2,4,5}$ Such hierarchical structures abound in nature; sophisticated organic-inorganic hybrids are also found in teeth, bones, seashells and exoskeletons. These hierarchical architectures emerging from self-organization under ambient conditions provide a sophisticated textbook for materials science. In recent decades, scientists have thus aspired to mimic hierarchical structures in nature and exploit biomimetic approaches to create new artificial materials with hierarchical structures and tailored properties. ${ }^{1,2,4,6,7}$ In this context, hierarchical molecular assembly has drawn increasing interest because of the possibility of fabricating highly ordered, functional superstructures from elemental building units and nanocrystals. Although hierarchical self-assembly of new artificial materials is a key concept in this field, de novo materials design for fabricating whole 3D structures at nanoscale precision is still a major challenge.

As a new direction for hierarchical self-assembly, dimensionreduced approaches such as layering $2 \mathrm{D}$ nanostructures become an important target for the rational design of precisely controlled lamellar nanomaterials with tailored properties. ${ }^{8,9}$ Of several possible strategies, one emerging route is through modular assembly of $2 \mathrm{D}$ building blocks. This strategy has been driven by the recent developments of well-defined 2D building blocks such as graphene $\mathrm{e}^{10,11}$ and various inorganic nanosheets. ${ }^{12-20} 2 \mathrm{D}$ nanosheets, which possess atomic or molecular thicknesses and infinite planar lengths, are regarded as the thinnest functional nanomaterials. Pioneering studies in this area appeared in the mid-1990s by one of the authors (T.S.), who reported the successful delamination of layered titanates into single titanate nanosheets. ${ }^{21,22}$ Prompted by this finding, several strategies to develop functional oxide nanosheets can be found in the recent literature. Additionally, the discovery of graphene has created a great sensation because of its fascinating properties within 2D material systems. ${ }^{10,11}$ These breakthroughs in 2D nanosheets have enabled the possibility of isolating and exploring the fascinating properties of $2 \mathrm{D}$ nanosheets of other layered materials; exfoliation into single atomic layers will offer functional flexibility, new properties and novel applications. Much effort has been devoted to synthesizing $2 \mathrm{D}$ nanosheets of various inorganic materials, including metal oxides, ${ }^{12-14,16}$ hydroxides ${ }^{23}$ and transition-metal chalcogenides, ${ }^{17,19}$ as well as to investigating their unique electronic structures and physical properties.

One important and attractive aspect of these exfoliated nanosheets is that various nanostructures can be fabricated using these nanosheets as $2 \mathrm{D}$ building blocks. ${ }^{14,24}$ In practice, colloidal nanosheets can be organized into various nanostructures or combined with a range of foreign materials at the nanometer scale by applying solution-based synthetic techniques involving layer-by-layer (LbL) self-assembly and flocculation. It is even possible to tailor superlattice-like assemblies by fusing and/or assembling a wide range of materials such as organic molecules, gels, polymers and inorganic nanoparticles. Sophisticated functionalities or nanodevices, as well as precise control over their arrangement at the molecular scale, may be designed through the selection of nanosheets and combining materials. Such soft-chemical protocols relying on the use of $2 \mathrm{D}$ building blocks and operating at room temperature enable pathways to create new artificial materials 
with kinetically controlled, hierarchical nanoarchitectures and tailored properties.

In this Focus Review, we provide an overview of new design principles for hierarchical nanoarchitectures using LbL assembly of 2D oxide nanosheets. Among the types of 2D inorganic nanosheets, oxide nanosheets are important and fascinating research targets that are being pursued because of the almost infinite varieties of layered oxide materials with interesting functional properties. ${ }^{12-14,16,25}$ Oxide nanosheets have distinct differences and advantages compared with graphene and other 2D nanosheets because of their potential to be used as insulators, semiconductors and even conductors, depending on their chemical composition and the structures of the parent layered compounds. Oxide nanosheets also have remarkable potential as building blocks for tailoring new fusion materials combined with a wide range of foreign materials such as organic molecules, gels, polymers and inorganic nanoparticles. We present a perspective on the advantages offered by nanosheet architectures for various applications in optoelectronics, spinelectronics, energy and environmental technologies.

\section{SYNTHESIS OF 2D OXIDE NANOSHEETS}

A variety of metal oxide nanosheets have been synthesized by delaminating the precursors of layered oxides into their elemental layers (Table 1, Figure 1). Chemical exfoliation is the easiest route for isolating unilamellar nanosheets from layered oxides. Exfoliation is generally achieved via a high degree of swelling, typically driven by intercalation of bulky organic ions (for example, quaternary ammonium cations and propylammonium cations) in the layered oxides. $^{21,22,26,27}$ This soft-chemical exfoliation has attracted much attention as an efficient method for preparing large amounts of colloidal suspensions, in which oxide nanosheets are highly dispersed in an aqueous media (Figure $1 \mathrm{~b}$ ). So far, diverse layered metal oxides (for example, $\quad \mathrm{Cs}_{0.7} \mathrm{Ti}_{1.825} \mathrm{O}_{4}, \quad \mathrm{~K}_{0.8} \mathrm{Ti}_{1.2} \mathrm{Fe}_{0.8} \mathrm{O}_{4}, \quad \mathrm{~K}_{0.8} \mathrm{Ti}_{1.6} \mathrm{Co}_{0.4} \mathrm{O}_{4}$,

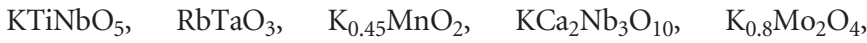
$\mathrm{K}_{0.2} \mathrm{RuO}_{2.1}$ and $\mathrm{Cs}_{6+x} \mathrm{~W}_{11} \mathrm{O}_{36}$ ) have been delaminated into their elemental layers. ${ }^{14}$ These host compounds are composed of stacked,

Table 1 Two-dimensional oxide nanosheets derived from chemical exfoliation

\begin{tabular}{|c|c|c|}
\hline \multicolumn{2}{|l|}{ Material } & $\begin{array}{l}\text { Property } \\
\text { Semiconducting }\end{array}$ \\
\hline $\mathrm{Ti}$ & $\mathrm{Ti}_{0.91} \mathrm{O}_{2}, \mathrm{Ti}_{0.87} \mathrm{O}_{2}, \mathrm{Ti}_{4} \mathrm{O}_{9}, \mathrm{Ti}_{5} \mathrm{O}_{11}$ & $\begin{array}{l}\text { Semiconducting } \\
\text { Photocatalytic } \\
\text { Dielectric }\end{array}$ \\
\hline & $\begin{array}{l}\mathrm{Ti}_{0.8} \mathrm{Co}_{0.2} \mathrm{O}_{2}, \mathrm{Ti}_{0.6} \mathrm{Fe}_{0.4} \mathrm{O}_{2}, \mathrm{Ti}_{(5.2-2 x) / 6} \mathrm{Mn}_{x / 2} \mathrm{O}_{2} \\
(0 \leqslant x \leqslant 0.4), \mathrm{Ti}_{0.8-x / 4} \mathrm{Fe}_{x / 2} \mathrm{Co}_{0.2-x / 4} \mathrm{O}_{2}(0 \leqslant x \leqslant 0.8)\end{array}$ & Ferromagnetic \\
\hline $\mathrm{Mn}$ & $\mathrm{MnO}_{2}$ & Redoxable \\
\hline $\mathrm{Nb}, \mathrm{Ti}-\mathrm{Nb}$ & $\mathrm{Nb}_{3} \mathrm{O}_{8}, \mathrm{Nb}_{6} \mathrm{O}_{17}, \mathrm{TiNbO}_{5}, \mathrm{Ti}_{2} \mathrm{NbO}_{7}, \mathrm{Ti}_{5} \mathrm{NbO}_{14}$ & $\begin{array}{l}\text { Photocatalytic } \\
\text { Dielectric }\end{array}$ \\
\hline $\mathrm{Ta}$ & $\mathrm{TaO}_{3}$ & Electrolyte \\
\hline Perovskite & $\begin{array}{l}\mathrm{LaNb}_{2} \mathrm{O}_{7},(\mathrm{Ca}, \mathrm{Sr})_{2} \mathrm{Nb}_{3} \mathrm{O}_{10},(\mathrm{Ca}, \mathrm{Sr})_{2} \mathrm{Ta}_{3} \mathrm{O}_{10} \\
\mathrm{Ca}_{2} \mathrm{Na}_{m-3} \mathrm{Nb}_{m} \mathrm{O}_{3 m+1}(m=3-6), \mathrm{SrTa}_{2} \mathrm{O}_{7}, \mathrm{Bi}_{2} \mathrm{Sr}- \\
\mathrm{Ta}_{2} \mathrm{O}_{9}, \mathrm{Bi}_{4} \mathrm{Ti}_{3} \mathrm{O}_{12}\end{array}$ & $\begin{array}{l}\text { Photocatalytic } \\
\text { Dielectric }\end{array}$ \\
\hline & $\begin{array}{l}\mathrm{La}_{0.9} \mathrm{Eu}_{0.05} \mathrm{Nb}_{2} \mathrm{O}_{7}, \mathrm{La}_{0.7} \mathrm{~Tb}_{0.3} \mathrm{Ta}_{2} \mathrm{O}_{7}, \mathrm{Eu}_{0.56} \mathrm{Ta}_{2} \mathrm{O}_{7}, \\
\mathrm{Gd}_{1.4} \mathrm{Eu}_{0.6} \mathrm{Ti}_{3} \mathrm{O}_{10}, \mathrm{Bi}_{2} \mathrm{SrTa}_{2} \mathrm{O}_{9}\end{array}$ & Luminescence \\
\hline Mo & $\mathrm{MoO}_{2}$ & Conducting \\
\hline $\mathrm{Ru}$ & $\mathrm{RuO}_{2.1}, \mathrm{RuO}_{2}$ & $\begin{array}{l}\text { Conducting } \\
\text { Redoxable }\end{array}$ \\
\hline W & $\mathrm{W}_{2} \mathrm{O}_{7}, \mathrm{Cs}_{4} \mathrm{~W}_{11} \mathrm{O}_{36}$ & $\begin{array}{l}\text { Redoxable } \\
\text { Photochromic }\end{array}$ \\
\hline
\end{tabular}

negatively charged slabs and alkali metal cations $\left(\mathrm{K}^{+}, \mathrm{Rb}^{+}, \mathrm{Cs}^{+}\right)$ occupying the interlayer space. A common feature of these layered oxides is their cation-exchange capacity involving interlayer alkali metal ions. Owing to their rich chemical reactivity involving the interlayer space, these layered oxides have been investigated as important targets for ion-exchange reactions and versatile intercalation chemistry for the fabrication of various hybrid materials. ${ }^{28,29}$ The ion exchange and intercalation properties also facilitate a high degree of swelling and total delamination into their elemental layers (nanosheets).

The starting layered oxides are usually synthesized by a conventional solid-state reaction at high temperature $\left(800-1300^{\circ} \mathrm{C}\right)$. Oxide nanosheets are synthesized using two-step soft-chemical reactions involving acid exchange and intercalation of tetrabutylammonium $\left(\mathrm{TBA}^{+}\right)$ions. Figure 2 shows a typical procedure for soft-chemical exfoliation of a layered perovsite $\left(\mathrm{KCa}_{2} \mathrm{Nb}_{3} \mathrm{O}_{10}\right)$. First, the layer oxides are treated in an acidic solution to produce their protonic form. The resulting protonic oxides are subsequently delaminated through reaction with a solution containing $\mathrm{TBA}^{+}$ions, producing turbid colloidal suspensions of oxide nanosheets (Figure 1b). The exfoliated nanosheets are characterized by a $2 \mathrm{D}$ single crystal with molecular thickness; in the case of $\mathrm{Ca}_{2} \mathrm{Nb}_{3} \mathrm{O}_{10}$, the thickness is only $\sim 1.5 \mathrm{~nm}$, corresponding to three $\mathrm{NbO}_{6}$ octahedral nanoblocks. This exfoliation process is quite general: using solution-based exfoliation techniques, it is possible to investigate dozens of different oxide nanosheets in the search for new phenomena and applications (Table 1).

These oxide nanosheets have distinct differences and advantages compared with graphene because of their potential to be used as insulators, semiconductors and even conductors, depending on their chemical composition and the structures of the parent-layered compounds. To date, these 2D oxide nanosheets have mainly been produced by delaminating the intrinsic layered structures of their bulk counterparts, which hinders further study of oxide nanosheets. To expand the utility of oxide nanosheets, lattice engineering and/or doping processes have recently been utilized for tailoring electronic properties. For this purpose, the exfoliation technique of layered compounds is very helpful for rationally designing oxide nanosheets with various functionalities. The composition of oxide nanosheets can be intentionally modified and tuned by the substitution and incorporation of other elements into designated sites during the solid-state synthesis of bulk, layered compounds. Such lattice engineering is useful for designing dielectric, ${ }^{30-32}$ ferromagnetic ${ }^{33-36}$ and photoluminescent properties ${ }^{37-39}$ in oxide nanosheets.

In addition to these chemical approaches, some oxide nanosheets (for example, $\mathrm{Bi}_{2} \mathrm{Sr}_{2} \mathrm{CaCu}_{2} \mathrm{O}_{8}, \mathrm{MoO}_{3}$ ) can be prepared by mechanical separation with adhesive tapes. ${ }^{40}$ Other bottom-up synthetic protocols have also been explored to obtain oxide nanosheets. For example, single-domain, epitaxial $\mathrm{TiO}_{2-x}$ nanosheets can be obtained by electron beam evaporation of $\mathrm{Ti}$ in an oxidative atmosphere under UHV conditions on a Pt substrate. ${ }^{41} \mathrm{MnO}_{2}$ nanosheets can be directly obtained using a one-pot synthesis route involving chemical oxidation of $\mathrm{Mn}^{2+}$ in a tetramethylammonium aqueous solution. ${ }^{42}$ However, the resulting nanosheets are usually quite small with the lateral dimension less than $100 \mathrm{~nm}$. Additionally, the nanosheets, derived from mechanical separation and growth techniques, are formed in thin films on the substrate and are thus not applicable as precursors for hierarchical self-assembly. In this Focus Review, we focus mainly on our recent research on chemically derived nanosheets and their nanoarchitectures. 
a

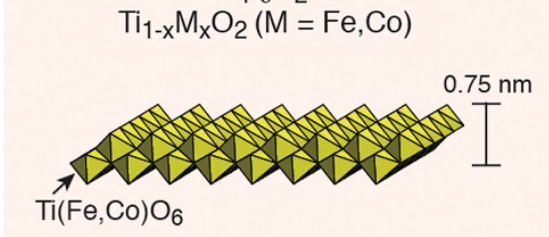

$\mathrm{Ca}_{2} \mathrm{Nb}_{3} \mathrm{O}_{10}$

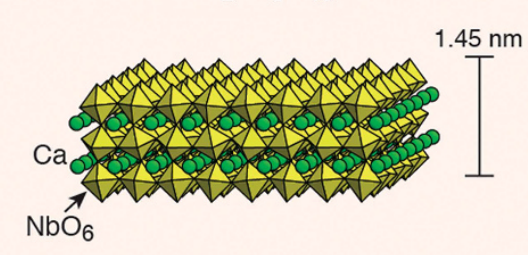

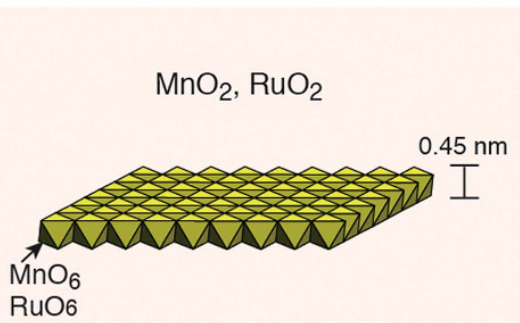

RuO6

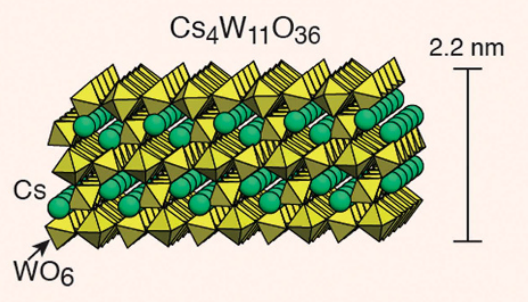

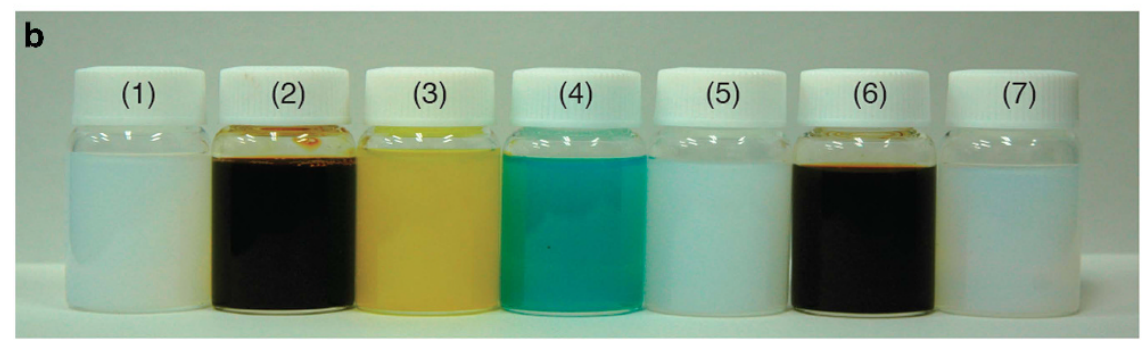

Figure 1 (a) Structures of typical oxide nanosheets. (b) Images of colloidal suspensions of oxide nanosheets: (1) $\mathrm{Ti}_{0.91} \mathrm{O}_{2}$ (semiconducting), (2) $\mathrm{MnO}_{2}$ (redox active), (3) $\mathrm{Ti}_{0.6} \mathrm{Fe}_{0.4} \mathrm{O}_{2}$ (ferromagnetic), (4) $\mathrm{Ti}_{0.8} \mathrm{Co}_{0.2} \mathrm{O}_{2}$ (ferromagnetic), (5) $\mathrm{Ca}_{2} \mathrm{Nb}_{3} \mathrm{O}_{10}$ (dielectric), (6) $\mathrm{RuO}_{2}$ (conducting) and (7) $\mathrm{Cs}_{4} \mathrm{~W}_{11} \mathrm{O}_{36}$ (photochromic). The colloidal suspension of $\mathrm{RuO}_{2}$ nanosheets was provided by Prof. W. Sugimoto (Shinshu University).

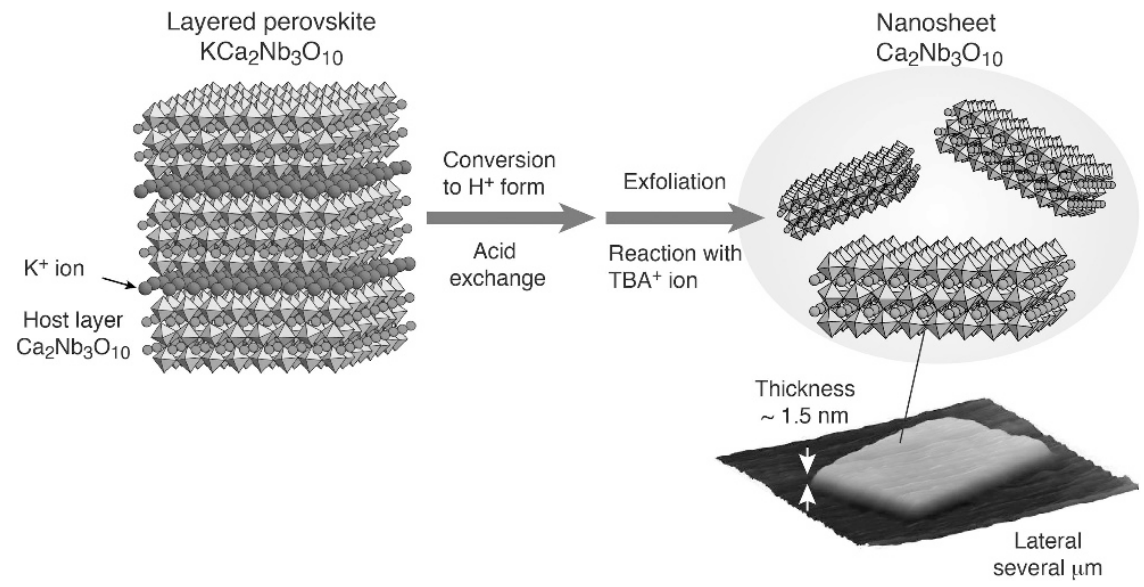

Figure 2 Schematic illustration of the crystal structure of a typical-layered perovskite $\left(\mathrm{KCa}_{2} \mathrm{Nb}_{3} \mathrm{O}_{10}\right)$ and its exfoliation into $\mathrm{Ca}_{2} \mathrm{Nb}_{3} \mathrm{O}_{10}$ nanosheets. A full color version of this figure is available at Polymer Journal online.

\section{NANOSHEET ARCHITECTONICS FOR HIERARCHICALLY STRUCTURED ASSEMBLY}

2D oxide nanosheets have remarkable potential as building blocks for hierarchically structured assemblies. Oxide nanosheets have some unique features: (i) they possess an extremely high $2 \mathrm{D}$ anisotropy with a molecular-level thickness of $0.5-3 \mathrm{~nm}$ and a bulk lateral size typically $>1 \mu \mathrm{m}$ and (ii) they are a $2 \mathrm{D}$ single crystal with a welldefined composition and structure inherited from a layered parent compound. In addition, these nanosheets are obtained as negatively charged crystallites that are dispersed in a colloidal suspension. These aspects make nanosheets a suitable building block for designing hierarchical nanoarchitectures.

In practice, colloidal nanosheets can be organized into various nanoarchitectures by applying solution-based synthetic techniques involving LbL self-assembly, ${ }^{14,24,43-46}$ flocculation $^{14,24}$ and hydrogelation (Figure 3). ${ }^{47}$ Through these processes, oxide nanosheets can be combined with a wide range of foreign materials such as organic polyelectrolytes, gels, metal complexes, clusters and even positively charged nanosheets, which is a major advantage of this approach. Furthermore, the shape can be controlled into thin flakes, hollow 


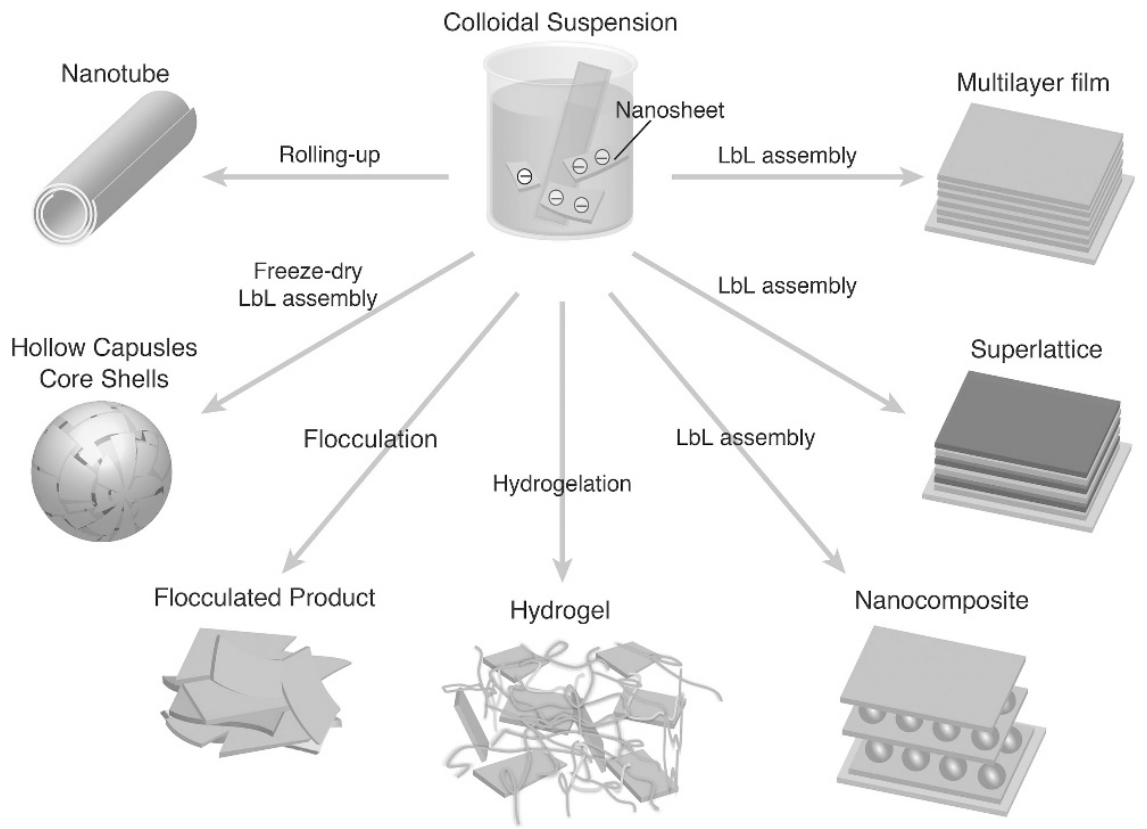

Figure 3 Schematic illustration showing approaches to form nanosheet architectures. A full color version of this figure is available at Polymer Journal online.

spheres and nanotubes through freeze-drying, spray-drying and rolling-up processes. ${ }^{12,14,24}$

One of the highlights of $2 \mathrm{D}$ nanosheets is the fabrication of hierarchical nanoarchitectures using LbL assembly of oxide nanosheets. Electrostatic LbL assembly via electrostatic sequential adsorption and Langmuir-Blodgett (LB) procedures is very effective for this purpose (Figure 4). Sequential LbL assembly is one of the most powerful methods for fabricating hierarchical nanoarchitectures and nanocomposite films with precisely controlled compositions, thicknesses and architectures on the nanometer scale. LbL self-assembly was first proposed by R. K. Iler ${ }^{48}$ and was applied to thin-film fabrication of oppositely charged inorganic microparticles in 1960s. This method was later revitalized by Decher et al. ${ }^{49}$ who demonstrated its applicability to a wide range of polyelectrolytes. This electrostatic LbL growth, often called 'molecular beaker epitaxy', became a major nanofabrication technique and is still in the forefront in research. In the case of oxide nanosheets, polycations such as poly(diallyldimethylammonium chloride) (PDDA) and poly(ethylenimine) are usually used as a counterpart of oxide nanosheets. A multilayer assembly can be built by alternately dipping the substrate in a colloidal suspension of oxide nanosheets and an aqueous solution of suitable polyelectrolytes (Figure 4a). ${ }^{43,44}$ Many research groups, including our own group, have demonstrated the applicability of this LbL technique to thin-film fabrication and ceramic nano-coatings using oxide nanosheets. ${ }^{14,22}$ Sequential deposition of various nanosheets also allows us to tailor the superlattices or heterostructures by tuning the number of nanosheets and their stacking sequences. Figure 5 depicts some examples of multilayer and superlattice assemblies. The observed changes in the ultraviolet-visible spectra and transmission electron microscopy images clearly indicated that the films grew as designed. Such LbL assemblies can also be used to construct fusion (hybrid) nanofilms by using different kinds of nanosheets ${ }^{50-53}$ or by coupling nanosheets with graphene, ${ }^{54}$ metal nanoparticles, ${ }^{24,55-57}$ nanotubes, ${ }^{55}$ functional molecules, ${ }^{58}$ etc. The superlattice approach enables the possibility of designing complex functions that cannot be achieved using a single material.
LB deposition has proven to be another effective approach for hierarchically structured assembly of 2D oxide nanosheets (Figure $4 \mathrm{~b}) .{ }^{45,46} \mathrm{LB}$ film deposition, in which a floating monolayer of material is formed on a water surface in a Langmuir trough followed by an appropriate level of compression, is preferable for achieving dense packing or orderly tiling. Through vertical dipping and lifting, the monolayer is transferred onto a flat substrate in a LbL manner. The LB technique has been used mainly for organic materials; however, it has been extended to a variety of inorganic nanomaterials. ${ }^{59}$ Pioneering work has demonstrated that exfoliated nanosheets can float by adhering to amphiphilic ammonium cations at the air-water interface through electrostatic interactions; thus, the ordinary LB procedure can be used to fabricate nanosheet films. Our recent studies on oxide nanosheets have demonstrated that the LB-based LbL approach with the use of an atomically flat substrate is effective for fabricating multilayer and superlattice nanofilms that are atomically uniform and highly dense (Figure 6).

Recent studies have shown that highly organized nanofilms of oxide nanosheets can be used to achieve some novel and useful properties for nanodevices. ${ }^{16,30,60,61}$ However, a big challenge is determining how to use this LbL assembly strategy to fabricate fully epitaxial nanofilms. In these LbL approaches, it is relatively easy to align the nanosheets parallel to the substrate surface, and the resultant materials have an ordered structure along the stacking direction. However, the in-plane azimuth orientation is usually random and the regularity is typically low, caused by the non-uniform geometric shape and the broad size distribution of nanosheet crystallites. The random nature in the inplane direction hinders the uses of resulting films for high-end nanoelectronics. However, we have observed promising signs that these problems can be circumvented by using monodisperse nanosheets.

\section{TAILORED FUSION MATERIALS BASED ON OXIDE NANOSHEETS}

There is enormous interest in building functional materials and devices based on hierarchically structured assemblies of 2D oxide 

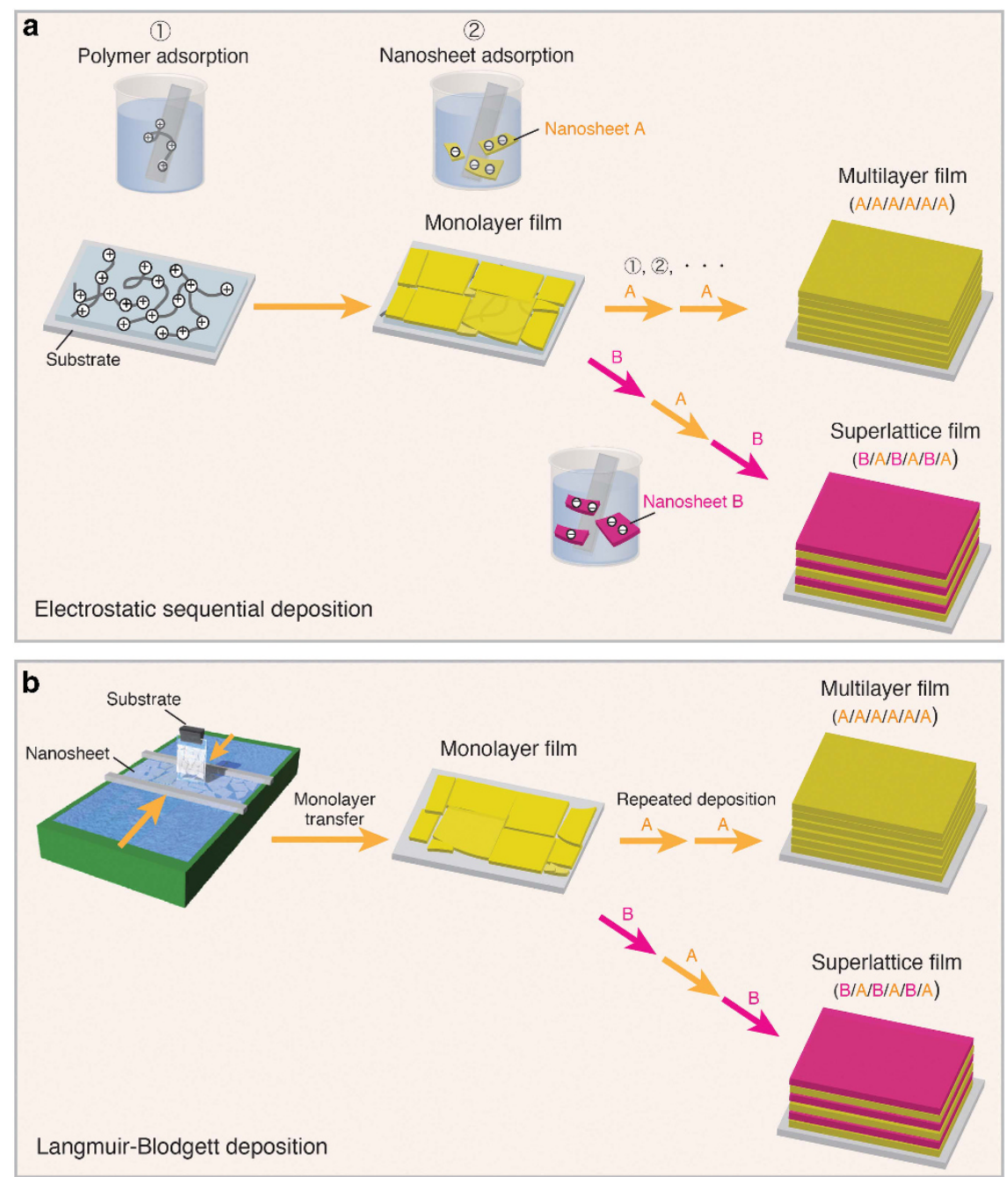

Figure 4 Schematic illustration of the layer-by-layer assembly of 2D oxide nanosheets. (a) Electrostatic sequential deposition and (b) the Langmuir-Blodgett process.

nanosheets (Figure 7). Thin-film device architectures based on 2D nanosheets have attracted considerable interest in recent years because of their intriguing physical properties and synergistic effects resulting from different 2D nanosheets. Van der Waals heterostructures based on graphene and other $2 \mathrm{D}$ analogues are one of the leading topics in materials science. ${ }^{62}$ A particular focus has been placed on establishing nanoarchitectonics of 2D nanosheets through finely controlled synthesis, hierarchically structured assemblies and device design. The resulting stack represents an artificial material assembled in a chosen sequence-as in building with LEGOs—with blocks defined with one atomic layer precision.

2D oxide nanosheets have recently become a unique playground for such LEGO-like games. Oxide nanosheets are exceptionally rich in structural diversity and electronic properties; oxide nanosheets exist in a variety of classes of functional materials, including metals, semiconductors, insulators (dielectrics) and magnetic materials. As a result, we may be able to control or design functionalities by tailoring the nanostructures and interfaces of a range of nanosheets and functional modules. Considering this fact along with the limitless possible combinations of nanosheets and other modules, we foresee developing more complex nanoarchitectures that exhibit a wide range of new and sophisticated functions even beyond graphene. In this context, we utilized oxide nanosheets as a building block in the LEGO-like bottom-up fabrication and successfully developed various functional nanodevices such as high permittivity (high- $\kappa$ ) nanocapacitors, all nanosheet field-effect transistors, artificial $\mathrm{Pb}$-free ferroelectrics, magnetic superlattices (spinelectronic devices), plasmonic materials, Li-ion batteries, supercapacitors, photovoltaics and photon-harvesting systems (Figure 7).

The development of oxide nanosheets with a wide range of conducting properties is very important in the design of nanodevices with sophisticated functionalities. Most oxide nanosheets synthesized to date are $d^{0}$ transition metal oxides $\left(\mathrm{Ti}^{4+}, \mathrm{Nb}^{5+}, \mathrm{Ta}^{5+}\right.$ or $\left.\mathrm{W}^{6+}\right)$ with a wide optical bandgap. ${ }^{16}$ Such $d^{0}$ oxide nanosheets are not electronically interesting but are useful as semiconducting or insulating materials. A few exceptions include $\mathrm{MnO}_{2}, \mathrm{MoO}_{2}, \mathrm{RuO}_{2.1}$ and $\mathrm{RuO}_{2}$, which are either redox-active or conducting. $\mathrm{RuO}_{2.1}$ and $\mathrm{RuO}_{2}$ nanosheets exhibited high electronic conductivity with a value of $10^{-4} \Omega \mathrm{cm}$, which is similar to that of transparent conducting oxide films (such as ITO). ${ }^{63,64}$

Thus, current research on oxide nanosheets has focused on their use as a semiconducting host or a dielectric nanoblock. ${ }^{16}$ Recently, we have discovered high- $\kappa$ oxide nanosheets $\left(\mathrm{Ti}_{0.87} \mathrm{O}_{2}, \mathrm{Ti}_{2} \mathrm{NbO}_{7}, \mathrm{LaNb}_{2} \mathrm{O}_{7}\right.$ and $\left.\mathrm{Ca}_{2-x} \mathrm{Sr}_{x} \mathrm{Nb}_{3} \mathrm{O}_{10}\right)$ that are an important material platform for 

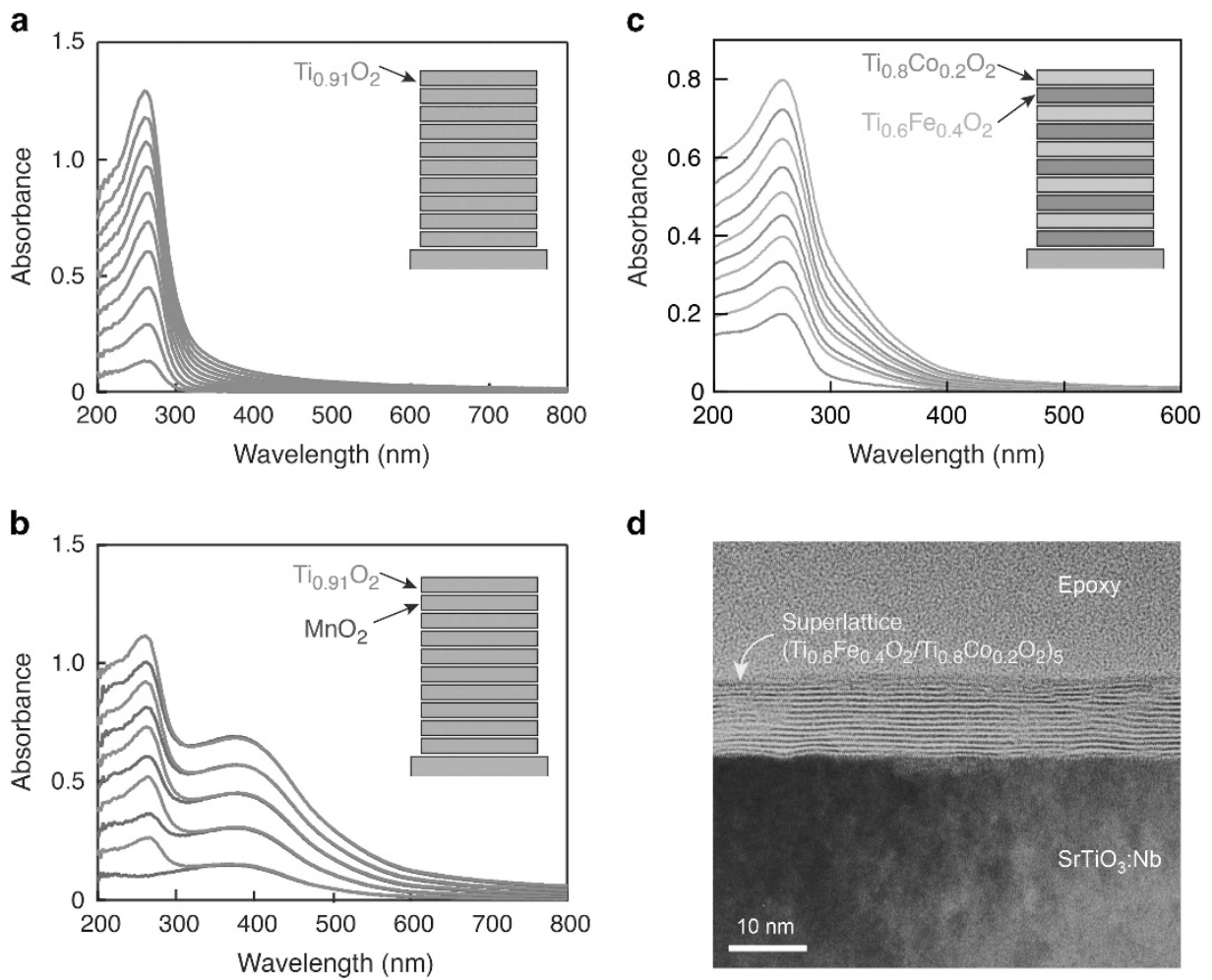

Figure 5 Electrostatic sequential deposition of 2D oxide nanosheets. (a) Ultraviolet-visible absorption spectra of $\left(\mathrm{Ti}_{0.91} \mathrm{O}_{2} / \mathrm{PDDA}\right)_{10}$ and $\left(\mathrm{Ti}_{0.91} \mathrm{O}_{2} / \mathrm{PDDA} / \mathrm{MnO}_{2} /\right.$ PDDA $)_{5}$ on quartz glass substrates. Reprinted with permission from Osada and Sasaki, ${ }^{13}$ Copyright 2009 by the Royal Society of Chemistry (b) Ultraviolet-visible absorption spectra and high-resolution transmission electron microscopy image of a superlattice assembly of ferromagnetic nanosheets $\left(\mathrm{Ti}_{0.6} \mathrm{Fe}_{0.4} \mathrm{O}_{2} / \mathrm{PDDA} / \mathrm{Ti}_{0.8} \mathrm{Co}_{0.2} \mathrm{O}_{2} / \mathrm{PDDA}\right)_{5}$. Reprinted with permission from Osada et al., 69 Copyright 2011 by the American Chemical Society. A full color version of this figure is available at Polymer Journal online.
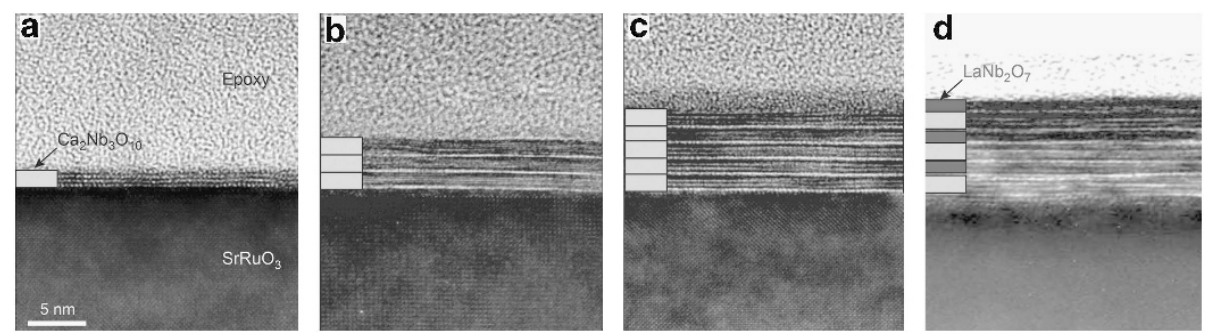

Figure 6 Transmission electron microscopy images of multilayer and superlattice films assembled from perovskite nanosheets $\left(\mathrm{Ca}_{2} \mathrm{Nb}_{3} \mathrm{O}_{10}\right.$ and $\left.\mathrm{LaNb}_{2} \mathrm{O}_{7}\right)$. (a) $\left(\mathrm{Ca}_{2} \mathrm{Nb}_{3} \mathrm{O}_{10}\right)_{1}$, (b) $\left(\mathrm{Ca}_{2} \mathrm{Nb}_{3} \mathrm{O}_{10}\right)_{3}$, (c) $\left(\mathrm{Ca}_{2} \mathrm{Nb}_{3} \mathrm{O}_{10}\right)_{5}$ and (d) $\left(\mathrm{LaNb}_{2} \mathrm{O}_{7} / \mathrm{Ca}_{2} \mathrm{Nb}_{3} \mathrm{O}_{10}\right)_{3}$. These nanoarchitectures were fabricated by layer-by-layer assembly using the LB process. Reprinted with permission from Osada et al., ${ }^{16}$ Copyright 2012 by Wiley and Li et al., ${ }^{68}$ Copyright 2011 by the American Chemical Society. A full color version of this figure is available at Polymer Journal online.

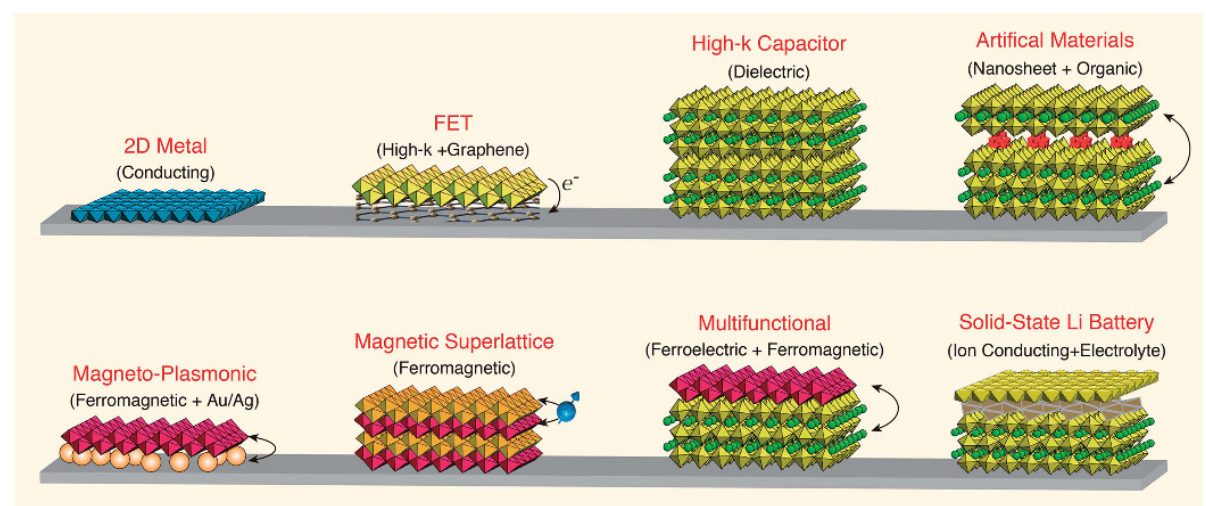

Figure 7 Tailored nanodevices from solution-based assembly of 2D oxide nanosheets. 

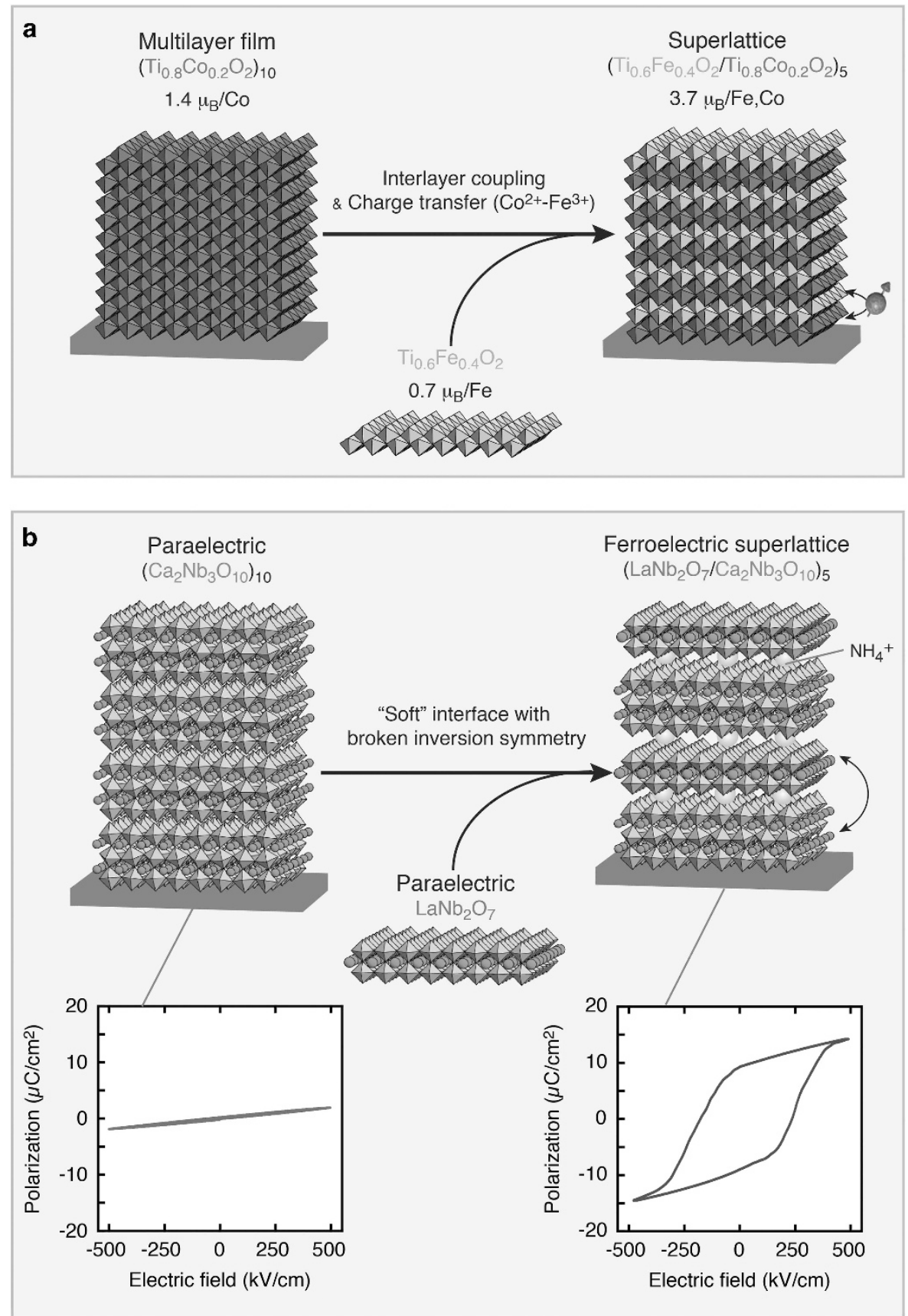

Figure 8 Superlattice engineering of 2D oxide nanosheets. (a) Artificially constructed ferromagnet based on ferromagnetic nanosheets $\left(\mathrm{Ti}_{0.8} \mathrm{CO}_{0.2} \mathrm{O}_{2}\right.$, $\left.\mathrm{Ti}_{0.6} \mathrm{Fe}_{0.4} \mathrm{O}_{2}\right){ }^{49,68}$ Such a superlattice exhibited a gigantic magnetic response, which stemmed from the interlayer $d$ - $d$ transitions $\left(\mathrm{Co}^{2+}-\mathrm{Fe}^{3+}\right)$ between adjacent nanosheets. (b) Artificial superlattice assembled from perovskite nanosheets. ${ }^{52}$ In contrast with the paraelectric nature of $\mathrm{Ca}_{2} \mathrm{Nb}_{3} \mathrm{O}_{10}$, the $\left(\mathrm{LaNb}_{2} \mathrm{O}_{7} /\right.$ $\mathrm{Ca}_{2} \mathrm{Nb}_{3} \mathrm{O}_{10}$ ) superlattice possesses a new form of interface coupling, which gives rise to ferroelectricity. A full color version of this figure is available at Polymer Journal online.

ultrascale electronic devices and post-graphene technology. Multilayer LB films of these nanosheets exhibited the highest permittivity $\left(\varepsilon_{\mathrm{r}}=200 \sim 320\right)$ ever realized in all known dielectrics in the ultrathin region $(<10 \mathrm{~nm}){ }^{30,61,65,66}$ Additionally, all of the high- $\kappa$ nanosheet capacitors $\left(\mathrm{RuO}_{2} / \mathrm{Ca}_{2} \mathrm{Nb}_{3} \mathrm{O}_{10} / \mathrm{RuO}_{2}\right)$ exceeded the performance of the state-of-the-art ceramic condensers, enabling a route for the development of next-generation capacitors and energy storage devices. ${ }^{67}$ One enticing possibility for using high- $\kappa$ dielectric nanosheets is $\mathrm{LbL}$ engineering of field-effect transistor devices combined with graphene and semiconducting nanosheets. ${ }^{13,68}$ Such a superlattice would allow the rational design of high-performance field-effect transistor devices, which realize mobility enhancement by dielectric screening. These topics are an important target for 'More \& Beyond Moore' technology promoted by the International Technology Roadmap for Semiconductors.

Hierarchically structured assemblies of 2D oxide nanosheets are also useful for the control of interlayer physical interactions and immobilization of functional nanostructures on device architectures. 
Combining different nanosheets into desired superlattice structures can produce new electronic states at the interface and the opportunity to create artificial materials with novel properties. Some examples of structures with these advantages were demonstrated by superlattices of ferromagnetic and dielectric nanosheets (Figure 8). Superlattices of ferromagnetic nanosheets $\left(\mathrm{Ti}_{0.8} \mathrm{Co}_{0.2} \mathrm{O}_{2}\right.$ and $\left.\mathrm{Ti}_{0.6} \mathrm{Fe}_{0.4} \mathrm{O}_{2}\right)$ exhibited a gigantic magneto-optical response $\left(\sim 3 \times 10^{5} \mathrm{deg} \mathrm{cm}^{-1}\right)$ in the visible wavelength region, which stemmed from the interlayer $d-d$ transitions $\left(\mathrm{Co}^{2+}-\mathrm{Fe}^{3+}\right)$ between adjacent nanosheets (Figure 8a). ${ }^{50,69}$ Thus, this superlattice is regarded as an artificially constructed ferromagnet, in which the charge, spin and orbital degree of freedoms might be strongly coupled at the interface. Layering combinations can be created with infinite varieties, and artificial layered structures with enhanced interface interactions can be formed with a great freedom of design. This architectonics concept can be utilized for designing nanostructured ferroelectrics. ${ }^{53}$ We fabricated an artificial superlattice by alternately stacking two different dielectric nanosheets $\left(\mathrm{Ca}_{2} \mathrm{Nb}_{3} \mathrm{O}_{10}\right.$ and $\mathrm{LaNb}_{2} \mathrm{O}_{7}$ ) (Figure $8 \mathrm{~b}$ ). Owing to this artificial structuring, we found that the $\mathrm{Ca}_{2} \mathrm{Nb}_{3} \mathrm{O}_{10} / \mathrm{LaNb}_{2} \mathrm{O}_{7}$ superlattice possesses a new form of interface coupling, which gives rise to ferroelectricity at room temperature. This artificial superlattice exhibited robust ferroelectricity even at several nanometer thicknesses, which is essentially required for future memory.

Oxide nanosheets offer the potential of use in various photonic devices, including use in photocatalysis, photoluminescence, photoconducting, fabricating photonic crystals, etc. For example, multilayer films of titanate and niobate nanosheets have been reported to be an excellent material for photocatalysts. ${ }^{70,71}$ In addition, the excellent dielectric properties of oxide nanosheets may allow the development of photonic crystals with a 1D periodic structure in which the position, width and reflectivity of a stop band are governed by the layer thickness, total number of layers and the difference between refractive indices of the two constitute materials in the photonic crystals.

The growing interest in nanosheet architectonics is not limited to electronic devices but also illustrates a new route for energy and environmental technologies. Important and attractive topics include: (i) $\mathrm{Pb}$-free ferroelectrics, ${ }^{53,72}$ (ii) nanosheet supercapacitors, ${ }^{63,73}$ (iii) solid-state Li-ion batteries ${ }^{74}$ and (iv) plasmonic photovoltaics ${ }^{57}$ / sensors. ${ }^{75}$ For example, we recently developed new magnetoplasmonic nanoarchitectures consisting of 1-nm-thick ferromagnetic nanosheets $\left(\mathrm{Ti}_{0.8} \mathrm{Co}_{0.2} \mathrm{O}_{2}\right)$ and $\mathrm{Au}$ nanoparticles. ${ }^{75}$ This magnetoplasmonic nanosystem showed surface plasmon resonance and magneto-optical activity, which is appealing for new applications in all-optical magnetic data storage and nano-sensing. Further integration to produce photocatalytic, photochromic, redoxable and photoluminescent nanosheets could lead to unified optoelectronic and photon-harvesting systems, such as visible-active photocatalysts, photon-harvesting systems and light-emitting devices. In this context, the rational design of multilayer films based on oxide nanosheets with photon-harvesting components, electron donors and electron acceptors is of great interest because it might mimic natural photosynthetic systems.

\section{SUMMARY AND OUTLOOK}

In this Focus Review, we briefly overviewed our recent research on nanosheet architectonics for innovative materials and devices. Some examples indicate the potential importance of nanosheet architectonics for designing new artificial materials with hierarchical structures and tailored properties. Artificially structured layered materials are capable of expressing novel properties based on the creation of new interfaces and layer interactions.

There is enormous interest in building functional materials and devices based on hierarchically structured assembly of 2D oxide nanosheets. Thin-film device architectures based on 2D nanosheets have attracted considerable interest in recent years because of their intriguing physical properties and the synergistic effects resulting from different 2D nanosheets. The resultant stack represents an artificial material assembled in a chosen sequence-as in building with LEGO - with blocks defined with one atomic layer precision. 2D oxide nanosheets are a unique playground for such LEGO-like games. Oxide nanosheets are exceptionally rich in structural diversity and electronic properties; oxide nanosheets exist in a variety of classes of functional materials, including metals, semiconductors, insulators (dielectrics) and magnetic materials. As a result, we may be able to control or design functionalities by tailoring the nanostructures and interfaces of a range of nanosheets and functional modules.

In terms of technological applications, we focused only on some examples of electronic applications. However, considering the limitless possible combinations of nanosheets and other modules, we foresee developing fusion materials and more complex nanoarchitectures that exhibit a wide range of new and sophisticated functions.

We hope that all of the aspects described here demonstrate the great potential of oxide nanosheets, including the introduction of more exciting properties and their potential use in a wide-range of future applications. Additionally, these prospects invite multidisciplinary and collaborative research with polymer scientists.

\section{ACKNOWLEDGEMENTS}

We are grateful to Dr Y Ebina, Dr R Ma, Dr TC Ozawa, Dr N Sakai, Dr B-W Li, Dr K Tsukagoshi (NIMS), Professor W Sugimoto (Shinshu University), Dr K Fukuda (Kyoto University) and Professor K Ono (KEK) for their experimental contributions and stimulating discussions over the years of the authors' research on oxide nanosheets. This work was supported in part by the World Premier International Research Center Initiative (WPI Initiative on Materials Nanoarchitronics), MEXT, CREST, JST and the Grant-in-Aid for Scientific Research on Innovative Areas of 'Fusion Materials' (No. 2206), MEXT, Japan.

1 Mann, S. Biomineralization (Oxford University Press, Oxford, UK, 2001).

2 Kato, T., Sugawara, A. \& Hosoda, N. Calcium carbonate-organic hybrid materials. Adv Mater. 14, 869-877 (2002).

3 Cölfen, H. \& Mann, S. Higher-order organization by mesoscale self-assembly and transformation of hybrid nanostructures. Angew. Chem. Int. Ed. Engl. 42 2350-2365 (2003).

4 Kato, T. Polymer/calcium carbonate layered thin-film composites. Adv. Mater. 12 1543-1546 (2000).

5 Oaki, Y. \& Imai, H. The hierarchical architecture of nacre and its mimetic material. Angew. Chem. Int. Ed. 44, 6571-6575 (2005).

6 Mann, S. Molecular recognition in biomineralization. Nature 332, 119-124 (1988).

7 Addadi, L. \& Weiner, S. Control and design principles in biological mineralization. Angew. Chem. Int. Ed. 31, 153-169 (1992)

8 Ariga, K., Ji, Q., Hill, J. P., Bando, Y. \& Aono, M. Forming nanomaterials as layered functional structures toward materials nanoarchitectonics. NPG Asia Mater. 4, e17 (2012)

9 Ariga, K., Yamauchi, Y., Rydzek, G., Ji, Q., Yonamine, Y., Wu, K. C.-W. \& Hill, J. P. Layer-by-layer nanoarchitectonics: invention, innovation, and evolution. Chem. Lett. 43, 36-68 (2014).

10 Novoselov, K. S., Geim, A. K., Morozov, S. V., Jiang, D., Zhang, Y., Dubonos, S. V., Grigorieva, I. V. \& Firsov, A. A. Electric field effect in atomically thin carbon films. Science 306, 666-669 (2004).

11 Geim, A. K. \& Novoselov, K. S. The rise of graphene. Nat. Mater. 6, 183-191 (2007)

12 Sasaki, T. Fabrication of nanostructured functional materials using exfoliated nanosheets as a building block. J. Ceram. Soc. Jpn. 115, 9-16 (2007).

13 Osada, M. \& Sasaki, T. Exfoliated oxide nanosheets: new solution to nanoelectronics. J. Mater. Chem. 19, 2503-2511 (2009). 
$14 \mathrm{Ma}$, R. \& Sasaki, T. Nanosheets of oxides and hydroxides: ultimate 2D charge-bearing functional crystallites. Adv. Mater. 22, 5082-5104 (2010).

15 Mas-Ballesté, R., Gómez-Navarro, C., Gómez-Herrero, J. \& Zamora, F. 2D materials: to graphene and beyond. Nanoscale 3, 20-30 (2011).

16 Osada, M. \& Sasaki, T. Two-dimensional dielectric nanosheets: novel nanoelectronics from nanocrystal building blocks. Adv. Mater. 24, 210-228 (2012).

17 Chhowalla, M., Shin, H. S., Eda, G., Li, L-J., Loh, K. P. \& Zhang, H. The chemistry of two-dimensional layered transition metal dichalcogenide nanosheets. Nat. Chem. 5, 263-275 (2013).

18 Rao, C. N. R., Ramakrishna Matte, H. S. S. \& Maitra, U. Graphene analogues of inorganic layered materials. Angew. Chem. Int. Ed. 52, 13162-13185 (2013).

19 Balendhran, S., Walia, S., Nili, H., Ou, J. Z., Zhuiykov, S., Kaner, R. B., Sriram, S., Bhaskaran, M. \& Kalantar-zadeh, K. Two-dimensional molybdenum trioxide and dichalcogenides. Adv. Funct. Mater. 23, 3952-3970 (2013).

20 Naguib, M., Mochalin, V. N., Barsoum, M. W. \& Gogotsi, Y. MXenes: a new family of two-dimensional materials. Adv. Mater. 26, 992-1005 (2014).

21 Sasaki, T., Watanabe, M., Hashizume, H., Yamada, H. \& Nakazawa, H. Macromoleculelike aspects for a colloidal suspension of an exfoliated titanate. Pairwise association of nanosheets and dynamic reassembling process initiated from it. J. Am. Chem. Soc. 118, 8329-8335 (1996).

22 Sasaki, T. \& Watanabe, M. Osmotic swelling to exfoliation. Exceptionally high degrees of hydration of a layered titanate. J. Am. Chem. Soc. 120, 4682-4689 (1998).

$23 \mathrm{Ma}$, R., Liu, Z., Li, L., lyi, N. \& Sasaki, T. Exfoliating layered double hydroxides in formamide: a method to obtain positively charged nanosheets. J. Mater. Chem. 16, 3809-3813 (2006).

24 Gunjakar, J. L., Kim, I. Y., Lee, J. M., Jo, Y. K. \& Hwang, S.-J. Exploration of nanostructured functional materials based on hybridization of inorganic 2D nanosheets. J. Phys. Chem. C 118, 3847-3863 (2014).

25 Wang L. \& Sasaki T. Titanium oxide nanosheets: graphene analogues with versatile functionalities. Chem. Rev. 114, 9455-9486 (2014)

26 Geng, F., Ma, R., Nakamura, A., Akatsuka, K., Ebina, Y., Yamauchi, Y., Miyamoto, N., Tateyama, Y. \& Sasaki, T. Unusually stable $\sim 100$-fold reversible and instantaneous swelling of inorganic layered materials. Nat. Commun. 4, 1632 (2013).

27 Geng, F., Ma, R., Ebina, Y., Yamauchi, Y., Miyamoto, N. \& Sasaki, T. Gigantic swelling of inorganic layered materials: a bridge to molecularly thin two-dimensional nanosheets. J. Am. Chem. Soc. 136, 5491-5500 (2014)

28 Gopalakrishnan, J. Chimie douce approaches to the synthesis of metastable oxide materials. Chem. Mater. 7, 1265-1275 (1995).

29 Schaak, R. E. \& Mallouk, T. E. Perovskites by design: a toolbox of solid-state reactions. Chem. Mater. 14, 1455-1471 (2002).

30 Osada, M., Takanashi, G., Li, B-W., Akatsuka, K., Ebina, Y., Ono, K., Funakubo, H., Takada, K. \& Sasaki, T. Controlled polarizability of one-nanometer-thick oxide nanosheets for tailored, high- $\kappa$ nanodielectrics. Adv. Funct. Mater. 21 , 3482-3487 (2011).

31 Osada, M. \& Sasaki, T. A- and B-site modified perovskite nanosheets and their integrations into high-k dielectric thin films. Int. J. Appl. Ceram. Tech. 9, 29-36 (2012)

32 Ebina, Y., Akatsuka, K., Fukuda, K. \& Sasaki, T. Synthesis and in situ X-ray diffraction characterization of two-dimensional perovskite-type oxide colloids with a controlled molecular thickness. Chem. Mater. 24, 4201-4208 (2012).

33 Osada, M., Ebina, Y., Fukuda, K., Ono, K., Takada, K., Yamaura, K. Takayama-Muromachi, E. \& Sasaki, T. Ferromagnetism in two-dimensional $\mathrm{Ti}_{0.8} \mathrm{C}_{0.2} \mathrm{O}_{2}$ nanosheets. Phys. Rev. B 73, 153301 (2006).

34 Osada, M., Itose, M., Ebina, Y., Ono, K., Ueda, S., Kobayashi, K. \& Sasaki, T. Gigantic magneto-optical effects induced by $(\mathrm{Fe} / \mathrm{Co})$-cosubstitution in titania nanosheets. Appl. Phys. Lett. 92, 253110 (2008).

35 Dong, X., Osada, M., Ueda, H., Ebina, Y., Kotani, Y., Ono, K., Ueda, S. Kobayashi, K., Takada, K. \& Sasaki, T. Synthesis of Mn-substituted titania nanosheets and ferromagnetic thin films with controlled doping. Chem. Mater. 21, 4366-4373 (2009).

36 Osada, M., Yoguchi, S., Itose, M., Li, B-W., Ebina, Y., Fukuda, K., Kotani, Y., Ono, K., Ueda, S. \& Sasaki, T. Controlled doping of semiconducting titania nanosheets for tailored spinelectronic materials. Nanoscale 6, 14227-14236 (2014).

37 Ozawa, T. C., Fukuda, K., Akatsuka, K., Ebina, Y. \& Sasaki, T. Preparation and characterization of the $\mathrm{Eu}^{3+}$ doped perovskite nanosheet phosphor: $\mathrm{La}_{0.90} \mathrm{Eu}_{0.05} \mathrm{Nb}_{2} \mathrm{O}_{7}$. Chem. Mater. 19, 6575-6580 (2007).

38 Ozawa, T. C., Fukuda, K., Akatsuka, K., Ebina, Y., Sasaki, T., Kurashima, K. \& Kosuda, $\mathrm{K}$. $\left(\mathrm{K}_{1.5} \mathrm{Eu}_{0.5}\right) \mathrm{Ta}_{3} \mathrm{O}_{10}$ : a far-red luminescent nanosheet phosphor with the double perovskite structure. J. Phys. Chem. C 112, 17115-17120 (2008).

39 Ida, S., Ogata, C., Eguchi, M., Youngblood, W. J., Mallouk, T. E. \& Matsumoto, Y. Photoluminescence of perovskite nanosheets prepared by exfoliation of layered oxides, $\mathrm{K}_{2} \mathrm{Ln}_{2} \mathrm{Ti}_{3} \mathrm{O}_{10}, \mathrm{KLnNb}_{2} \mathrm{O}_{7}$, and $\mathrm{RbLnTa}_{2} \mathrm{O}_{7}$ (Ln : lanthanide ion). J. Am. Chem. Soc. 130, 7052-7059 (2008)

40 Novoselov, K. S., Jiang, D., Schedin, F., Booth, T. J., Khotkevich, V. V., Morozov, S. V. \& Geim, A. K. Two-dimensional atomic crystals. Proc. Natl Acad. Sci. USA 102 10451-10453 (2005).

41 Orzali, T., Casarin, M., Granozzi, G., Sambi, M. \& Vittadini, A. Bottom-up assembly of single-domain titania nanosheets on (1x2)-Pt(110). Phys. Rev. Lett. 97, 156101 (2006).

42 Kai, K., Yoshida, Y., Kageyama, H., Saito, G., Ishigaki, T., Furukawa, Y. \& Kawamata, J. Room-temperature synthesis of manganese oxide monosheets. J. Am. Chem. Soc. 130, 15938-15943 (2008).
43 Sasaki, T., Ebina, Y., Tanaka, T., Harada, M., Watanabe, M. \& Decher, G. Layer-by-layer assembly of titania nanosheet/polycation composite films. Chem. Mater. 13, 4661-4667 (2001).

44 Tanaka, T., Fukuda, K., Ebina, Y., Takada, K. \& Sasaki, T. Highly organized selfassembled monolayer and multilayer films of titania nanosheets. Adv. Mater. 16, 872-875 (2004).

45 Muramatsu, M., Akatsuka, K., Ebina, Y., Wang, K. Z., Sasaki, T., Ishida, T., Miyake, K. \& Haga, M. Fabrication of densely packed titania nanosheet films on solid surface by use of Langmuir-Blodgett deposition method without amphiphilic additives. Langmuir 21, 6590-6595 (2005).

46 Akatsuka, K., Haga, M., Ebina, Y., Osada, M., Fukuda, K. \& Sasaki, T. Construction of highly ordered lamellar nanostructures through Langmuir-Blodgett deposition of molecularly thin titania nanosheets tens of micrometers wide and their excellent dielectric properties. ACS Nano 3, 1097-1106 (2009).

47 Liu, M., Ishida, Y., Ebina, Y., Sasaki, T. \& Aida, T. Photolatently modulable hydrogels using unilamellar titania nanosheets as photocatalytic crosslinkers. Nat. Commun. 4 , 2029 (2013).

48 Iler, R. K. Multilayers of colloidal particles. J. Colloid Inter. Sci. 21, 569-594 (1966).

49 Decher, G. Fuzzy nanoassemblies: toward layered polymeric multicomposites. Science 277, 1232-1237 (1997).

50 Osada, M., Ebina, Y., Takada, K. \& Sasaki, T. Gigantic magneto-optical effects in multilayer assemblies of two-dimensional titania nanosheets. Adv. Mater. 18, 295-299 (2006)

51 Li, L., Ma, R., Ebina, Y., Fukuda, K., Takada, K. \& Sasaki, T. Layer-by-layer assembly and spontaneous flocculation of oppositely charged oxide and hydroxide nanosheets into inorganic sandwich layered materials. J. Am. Chem. Soc. 129, 8000-8007 (2007).

52 Sakai, N., Fukuda, K., Omono, Y., Ebina, Y., Takada, K. \& Sasaki, T. Heteronanostructured films of titanium and manganese oxide nanosheets: photoinduced charge transfer and electrochemical properties. J. Phys. Chem. C 112, 5197-5202 (2008).

53 Li, B-W., Osada, M., Ozawa, T. C., Ebina, Y., Akatsuka, K., Ma, R., Funakubo, H. \& Sasaki, T. Engineered interfaces of artificial perovskite oxide superlattices via nanosheet deposition process. ACS Nano 4, 6673-6680 (2010).

54 Sun, P., Ma, R., Osada, M., Sasaki, T., Wei, J., Wang, K., Wu, D., Cheng, Y. \& Zhu, H. The formation of graphene-titania hybrid films and their resistance change under ultraviolet irradiation. Carbon 50, 4518-4523 (2012).

$55 \mathrm{Ma}$, R., Sasaki, T. \& Bando, Y. Layer-by-layer assembled multilayer films of titanate nanotubes, Ag- or Au-loaded nanotubes, and nanotubes/nanosheets with polycations. J. Am. Chem. Soc. 126, 10382-10388 (2004).

56 Wang, L. Z., Ebina, Y., Takada, K., Kurashima, K. \& Sasaki, T. A new mesoporous manganese oxide pillared with double layers of alumina. Adv. Mater. 16, 1412-1416 (2004).

57 Sakai, N., Sasaki, T., Matsubara, K. \& Tatsuma, T. Layer-by-layer assembly of gold nanoparticles with titania nanosheets: control of plasmon resonance and photovoltaic properties. J. Mater. Chem. 20, 4371-4378 (2010).

58 Akatsuka, K., Ebina, Y., Muramatsu, M., Sato, T., Hester, H., Kumaresan, D., Schmehl, R. H., Sasaki, T. \& Haga, M. Photoelectrochemical properties of alternating multilayer films composed of titania nanosheets and $\mathrm{Zn}$ porphyrin. Langmuir $\mathbf{2 3}$, 6730-6736 (2007).

59 Tao, A. R., Huang, J. \& Yang, P. Langmuir-Blodgettry of nanocrystals and nanowires. Acc. Chem. Res. 41, 1662-1673 (2008).

60 Osada, M., Akatsuka, K., Ebina, Y., Kotani, Y., Ono, K., Funakubo, H., Ueda, S., Kobayashi, K., Takada, K. \& Sasaki, T. Langmuir-Blodgett fabrication of nanosheetbased dielectric films without an interfacial dead layer. Jpn J. Appl. Phys. 47, 7556-7560 (2008)

61 Osada, M., Akatsuka, K., Ebina, Y., Funakubo, H., Ono, K., Takada, K. \& Sasaki, T. Robust high- $k$ response in molecularly thin perovskite nanosheets. ACS Nano 4, 5225-5232 (2010).

62 Geim, A. K. \& Grigorieva, I. V. Van der Waals heterostructures. Nature 499, 419-425 (2013)

63 Sugimoto, W., Iwata, H., Yasunaga, Y., Murakami, Y. \& Takasu, Y. Preparation of ruthenic acid nanosheets and utilization of its interlayer surface for electrochemical energy storage. Angew. Chem. Int. Ed. 42, 4092-4096 (2003).

64 Sato, J., Kato, H., Kimura, M., Fukuda, K. \& Sugimoto, W. Conductivity of ruthenate nanosheets prepared via electrostatic self-assembly: characterization of isolated single nanosheet crystallite to mono- and multilayer electrodes. Langmuir 26 , 18049-18054 (2010).

65 Osada, M., Ebina, Y., Funakubo, H., Yokoyama, S., Kiguchi, T., Takada, K. \& Sasaki, T. High-k dielectric nanofilms fabricated from titania nanosheets. Adv. Mater. 18, 1023-1027 (2006).

66 Li, B.-W., Osada, M., Ebina, Y., Akatsuka, K., Fukuda, K. \& Sasaki, T. High thermal robustness of molecularly thin perovskite nanosheets and implications for superior dielectric properties. ACS Nano 8, 5449-5461 (2014).

67 Wang, C., Osada, M., Ebina, Y., Li, B.-W., Akatsuka, K., Fukuda, K., Sugimoto, W., Ma, R. \& Sasaki, T. All-nanosheet ultrathin capacitors assembled layer-by-layer via solutionbased processes. ACS Nano 8, 2658-2666 (2014).

68 Li, W., Li, S.-L., Komatsu, K., Aparecido-Ferreira, A., Lin, Y.-F., Xu, Y., Osada, M., Sasaki, T. \& Tsukagoshi, K. Realization of graphene field-effect transistor with high- $k$ $\mathrm{HCa}_{2} \mathrm{Nb}_{3} \mathrm{O}_{10}$ nanoflake as top-gate dielectric. Appl. Phys. Lett. 103, 023113 (2013).

69 Osada, M., Sasaki, T., Ono, K., Kotani, Y., Ueda, S. \& Kobayashi, K. Orbital reconstruction and interface ferromagnetism in self-assembled nanosheet superlattices. ACS Nano 5, 6871-6879 (2011). 
70 Sakai, N., Fukuda, K., Shibata, T., Ebina, Y., Takada, K. \& Sasaki, T. Photoinduced hydrophilic conversion properties of titania nanosheets. J. Phys. Chem. B 110 6198-6203 (2006)

71 Shibata, T., Takanashi, G., Nakamura, T., Fukuda, K., Ebina, Y. \& Sasaki, T. Titanoniobate and niobate nanosheet photocatalysts: superior photoinduced hydrophilicity and enhanced thermal stability of unilamellar $\mathrm{Nb}_{3} \mathrm{O}_{8}$ nanosheet. Energy Environ. Sci. 4, 535-542 (2011).

72 Li, B.-W., Osada, M., Akatsuka, K., Ebina, Y., Ozawa, T. C. \& Sasaki, T. Solution-based fabrication of perovskite multilayers and superlattices using nanosheet process. Jpn. J. Appl. Phys. 50, 09NA10 (2011).
73 Makino, S., Shinohara, Y., Ban, T., Shimizu, W., Takahashi, K., Imanishi, N. \& Sugimoto, W. $4 \mathrm{~V}$ class aqueous hybrid electrochemical capacitor with battery-like capacity. RSC Adv. 2, 12144-12147 (2012).

74 Xu, X., Takada, K., Fukuda, K., Ohnishi, T., Akatsuka, K., Osada, M., Hang, B. T., Kumagai, K., Sekiguchi, T. \& Sasaki, T. Tantalum oxide nanomesh as self-standing one nanometre thick electrolyte. Energy Environ. Sci. 4 3509-3512 (2011).

75 Osada, M., Hajduková-Šmídová, N., Akatsuka, K., Yoguchi, S. \& Sasaki, T Gigantic plasmon resonance effects on magneto-optical activity of molecularly thin ferromagnets near gold surfaces. J. Mater. Chem. C 1, 2520-2524 (2013). 